\title{
Sulfonylureas in the Treatment of Type 2 Diabetes Mellitus: A Fresh Look and New Insights
}

\author{
Aus Alzaid
}

Received: January 29, 2020 / Published online: April 22, 2020

(C) The Author(s) 2020

Keywords: Cardiovascular outcomes; Guidelines; Sulfonylureas; Type 2 diabetes mellitus

\section{Key Summary Points}

In this editorial, the issues raised in each of the articles included in this supplement issue of Diabetes Therapy are introduced, including their focus on reappraisal of sulfonylureas (SUs) in the treatment of type 2 diabetes mellitus (T2DM).

SUs have been available for over 50 years, with the latest generation of SUs associated with effective antihyperglycaemic efficacy but a lower risk of adverse effects relative to earlier generations of SUs.

The wide clinical benefits of SU treatment in T2DM are reviewed in this supplement, as well as how international and national guidelines recommend their use in patients with T2DM.

Enhanced Digital Features To view digital features for this article go to https://doi.org/10.6084/m9.figshare. 12030267.

\section{A. Alzaid ( $\square)$}

Diabetes Consultant, PO Box 300064, Riyadh 11372, Saudi Arabia

e-mail: drausalzaid@hotmail.com
In recent years, remarkable changes have taken place in the treatment of type 2 diabetes mellitus (T2DM). The introduction of many new and exciting medications and drug classes have enriched and expanded the choice of therapies available to treat this increasingly prevalent and burdensome disease. In addition, the general approach to disease management has evolved from a strictly physician-driven treatment approach to an all-inclusive patientcentred care [1]. In the midst of the current change and adjustment however, it is incumbent upon us to reappraise the role of established medications, such as the sulfonylureas (SUs), in order to define their rightful place in this dynamic treatment landscape of T2DM therapies.

Since their first introduction into clinical practice over 50 years ago, SUs have incredibly maintained a consistent and strong presence as valuable agents in the treatment of T2DM [2]. The class itself has undergone structural and "generational" changes over the years, yielding modified medications that offer maximised efficacy with minimised risks of adverse effects [2]. SUs, especially later-generation ones, effectively lower blood glucose levels and have welldefined adverse events and cardiovascular safety profiles relative to other therapies [3-7]. 
A recent symposium, entitled "SUs in the treatment of T2DM: a fresh look and new insights" held on Wednesday September 18, 2019 during the 55th Annual Meeting of the European Association for the Study of Diabetes (EASD) in Barcelona, Spain, presented recent data for SUs, with the aim of going beyond the low cost and affordability of SUs to determine the main scientific evidence and wider clinical benefits behind the popular use of SUs in the treatment of T2DM. This supplement of Diabetes Therapy provides summaries of the three presentations made during the symposium by three international experts in the field.

In the first of these presentations, Dr Aslam Amod discusses his personal perspective of SUs, examining how this therapeutic class has performed in both local and international guidelines. In the second presentation, Professor Lawrence Leiter addresses the question of whether SUs have lived up to expectations on cardiovascular safety when directly tested against comparator agents in cardiovascular outcome trials. Finally, in the third presentation, in the context that T2DM is a progressive disease that commonly requires $>1$ drug to control the disease, Dr Miao Yu discusses whether SUs are a good team player and examines the likely implications of using SUs alone early in the disease, or in combination with other agents, on glycaemic outcomes and net side effects.

In conclusion, the old image of SUs as a source of troublesome hypoglycaemia and chequered cardiovascular adverse outcomes in the past is no longer considered tenable. A new generation of SUs deserves to be seen in a better light as clinical experience and a growing body of scientific evidence, including favourable results from recent cardiovascular outcome trials (CVOTs), indicate that modern SUs stand out clinically as safe and effective therapeutic agents in the treatment of T2DM. The fact that these agents also happen to be affordable should be seen as an added advantage, not an indication to limit their use to poor or underprivileged T2DM patients. Furthermore, headto-head CVOTs comparing SUs with newer medications are currently lacking. Until this has been scientifically addressed, the burden of proof for clinical superiority should not necessarily be laid on SUs or other comparator therapies. Future outcomes of the ongoing GRADE study [8] may shed further light on the metabolic benefits of SUs and their likely repositioning in the cascade of therapies used to treat T2DM. Revisiting SUs today is like catching up with an old and trusted friend, and we hope that the readers will find this fresh look at SUs to be informative and relevant to clinical practice.

\section{ACKNOWLEDGEMENTS}

Funding. Servier Medical Affairs, France, funded the development and publication of this article, including the journal's Rapid Service Fee.

Authorship. The author meets the International Committee of Medical Journal Editors (ICMJE) criteria for authorship for this article, takes responsibility for the integrity of the work as a whole, and has given their approval for this version to be published.

Medical Writing Assistance. The author would like to thank Andrea Bothwell, on behalf of Springer Healthcare Communications, who provided medical writing assistance with the first draft of this manuscript. This medical writing assistance was funded by Servier, France.

Prior Presentation. This article was based on the presentation given by the author at the symposium "SUs in the treatment of T2DM: a fresh look and new insights" during the 55th Annual Meeting of the European Association for the Study of Diabetes (EASD) held in September 2019 in Barcelona, Spain.

Disclosures. Aus Alzaid has participated in Speakers Bureau for Boehringer Ingleheim, Novartis and Servier, and served as a consultant to Servier. Aus Alzaid is currently retired and is not affiliated with any institution. 
Compliance with Ethics Guidelines. This article is based on previously conducted studies and does not contain any studies with human participants or animals performed by the authors.

Data Availability. Data sharing is not applicable to this article as no datasets were generated or analyzed during the current study.

Open Access. This article is licensed under a Creative Commons Attribution-NonCommercial 4.0 International License, which permits any non-commercial use, sharing, adaptation, distribution and reproduction in any medium or format, as long as you give appropriate credit to the original author(s) and the source, provide a link to the Creative Commons licence, and indicate if changes were made. The images or other third party material in this article are included in the article's Creative Commons licence, unless indicated otherwise in a credit line to the material. If material is not included in the article's Creative Commons licence and your intended use is not permitted by statutory regulation or exceeds the permitted use, you will need to obtain permission directly from the copyright holder. To view a copy of this licence, visit http://creativecommons.org/licenses/by$\mathrm{nc} / 4.0 /$.

\section{REFERENCES}

1. Powell PW, Corathers SD, Raymond J, Streisand R. New approaches to providing individualized diabetes care in the 21st century. Curr Diabetes Rev. 2015;11(4):222-30.

2. Sola D, Rossi L, Schianca GP, et al. Sulfonylureas and their use in clinical practice. Arch Med Sci. $2015 ; 11(4): 840-8$.

3. Leiter LA, Shestakova MV, Trubitsyna NP, Piletic M, Satman I. Implementing an optimized glucose-lowering strategy with a novel once daily modified release gliclazide formulation. Diabetes Res Clin Pract. 2016;112:50-6.

4. Maloney A, Rosenstock J, Fonseca V. A model-based meta-analysis of 24 antihyperglycemic drugs for type 2 diabetes: comparison of treatment effects at therapeutic doses. Clin Pharmacol Ther. 2019;105(5): 1213-23.

5. Schernthaner G, Grimaldi A, Di Mario U, et al. GUIDE study: double-blind comparison of once-daily gliclazide MR and glimepiride in type 2 diabetic patients. Eur J Clin Invest. 2004;34(8):535-42.

6. Vaccaro O, Masulli M, Nicolucci A, et al. Effects on the incidence of cardiovascular events of the addition of pioglitazone versus sulfonylureas in patients with type 2 diabetes inadequately controlled with metformin (TOSCA.IT): a randomised, multicentre trial. Lancet Diabetes Endocrinol. 2017;5(11):887-97.

7. Rosenstock J, Kahn SE, Johansen OE, et al. Effect of linagliptin vs glimepiride on major adverse cardiovascular outcomes in patients with type 2 diabetes: the CAROLINA randomized clinical trial. JAMA. 2019;322(12):1155-66.

8. Nathan DM, Buse JB, Kahn SE, et al. Rationale and design of the glycemia reduction approaches in diabetes: a comparative effectiveness study (GRADE). Diabetes Care. 2013;36(8):2254-61. 